\title{
LA RETÓRICA AUDIOVISUAL. EL RETO DE LA IMAGEN
}

\author{
Genara Pulido Tirado
}

Universidad de Jaén

1. En las últimas décadas las más variadas manifestaciones audiovisuales vienen cobrando una destacada importancia en el mundo occidental hasta llegar a cobrar un protagonismo que releva a un segundo lugar, al menos para la mayoría, las tradicionales manifestaciones escritas como es la literaria. Este hecho, junto a los avances que se están produciendo en el mundo de la información y las comunicaciones, está marcando, sin duda, una nueva época que entrevemos ya con cierta claridad y no sin una buena dosis de curiosidad y hasta de estupor.

La imagen se convierte así en un reto para los investigadores de la cultura en general, pues ni qué decir tiene que la aprehensión del mundo que nos rodea ha de ir precedida por el desciframiento de múltiples hechos que se nos muestran como imágenes de lectura difícil, polisémica y hasta equívoca no pocas veces, sobre todo en un momento en que parece que nuestras viejas «certezas realistas» están siendo sustituidas por una serie de simulacros que ocupan su lugar. 
El mundo audiovisual es extremadamente rico y complejo. Su presencia pronto desencadenó el interés de estudiosos que estaban desempeñando su labor en torno al fenómeno literario o comunicativo en general. La sistematización de tal interés, de cara a su estudio, se hizo posible gracias, sobre todo, a la semiótica, en cuyo seno llegó a constituirse una rama con características propias, la semiótica audiovisual, que cubrió un amplio campo constituido por manifestaciones tan variadas como el cine, la televisión, la propaganda, el cómic, etc. También hay que tener presente el destacado papel desempeñado por la teoría de la comunicación.

En lo que a la retórica se refiere, fue Roland Barthes el que se ocupó tempranamente de su estudio en este nuevo ámbito en un ensayo ya clásico, «Rhétorique de l'image» (1964). Con este estudio se iniciaba toda una serie de investigaciones de incalculable interés que irían evolucionando a la par de los sistemas teóricos imperantes en los distintos momentos en que se producían. Las características y evolución de estas investigaciones han sido estudiadas por distintos autores, que han trazado su historia teniendo en cuenta, fundamentalmente, su vinculación o autonomía en relación con la lingüística (Pérez Tornero, 1982: 119 y ss.; Rey, 1992: 27-81).

Tal hecho no es nada extraño, puesto que lo que se ha producido es un paso gradual desde la consideración del concepto de texto (cfr. Lotman, 1970: 69, 22; Viches, 19925: 19 ss.) como manifestación escrita (y ligada, por tanto, a la literaria) a la consideración de la imagen como texto, esto es, como lugar de producción e interpretación comunicativa en tanto que manifestación discursiva coherente a través de la cual se pueden llevar a cabo distintas estrategias de comunicación. La concepción semiótica de texto que podemos encontrar hoy como mecanismo semántico-pragmático que necesita ser actualizado mediante la interpretación permite estudiar bajo tal concepto una serie de manifestaciones culturales no literarias (entre las últimas, las audiovisuales tienen una gran importancia) que hasta hace poco tiempo estaban marginadas en este ámbito de estudio. Y es que lo textual, y la textualidad en general, considerados bajo una óptica semiótica, adquieren grandes dimensiones, por lo que no sorprende que Zunzunegui $\left(1992^{2}\right.$ : 78), tras definir el texto como "secuencia de signos que produce sentido», puntualice: «Texto en el que el sentido no se produce por la suma de significados parciales de los signos que lo componen, sino a través de su funcionamiento textual», lo que conlleva una elevada valoración de la coherencia textual, en la que habría que considerar un 
nivel expresivo, que distribuiría la información visual, y un nivel de contenido, en tanto que actualización del significado que llevaría a cabo el destinatario del discurso. En este sentido, el componente pragmático de la comunicación ha pasado a ocupar un lugar destacado desde el momento en que el receptor se integra en el proceso como elemento activo y fundamental.

Esta evolución y ampliación del concepto de texto ha estado marcada por la evolución de la semiótica (y de buena parte de los estudios literarios de distintas tendencias críticas) desde una concepción fundamentalmente linguiística a una concepción no lingüística, en la que se considera un conjunto amplio de elementos pertenecientes a distintas manifestaciones culturales, elementos que no utilizan como soporte un lenguaje con doble articulación como la lengua natural. Tal hecho fue más difícil de aceptar en la literatura, sin duda por usar como soporte una lengua, la literaria, pero lengua al fin y al cabo. En el campo (audio)visual la cuestión revistió no menos problemas, puesto que, aunque el soporte de la imagen no es una lengua articulada en sentido clásico, se intentó aplicar a las manifestaciones visuales las mismas categorías y procedimientos que a las lingüísticas. Y aquí hubo de operarse otro desplazamiento semántico en el término mismo de lengua$j e$, ya que, al igual que en el caso de texto, si hoy hablamos de lenguaje para aludir al cine, la televisión, la publicidad, la moda, etc., el término lenguaje se entiende en sentido amplio, como un mecanismo generador de significados y no como lenguaje articulado que puede manifestarse de forma oral o escrita, pero siempre sujeto a las leyes de la lengua cotidiana de la comunicación, leyes que se desviarán o romperán en las manifestaciones artísticas para diferenciarse así de la lengua coloquial.

En realidad, a lo que hemos asistido en las últimas décadas es a la tan conocida crisis de la literariedad, que ha repercutido no sólo en los estudios literarios, sino también en los artísticos en general, pues, al ampliar la concepción de lo artístico, se ha permitido la consideración y el estudio de manifestaciones culturales como las de carácter (audio)visual.

$\mathrm{Ni}$ qué decir tiene que la ampliación de las nociones de texto y lenguaje han ido unidas y se han producido no sólo por el agotamiento de los estudios lingüísticos en sentido estricto y la aparición de disciplinas de horizontes amplios, casi inabarcables, como la semiótica, sino también por la presión de necesidades concretas surgidas por los importantes avances tecnológicos que han provocado en este siglo un 
cambio fundamental en la sociedad y en nuestra manera de ver y abordar la rica y esquiva realidad que nos rodea. En este sentido, Zunzunegui $\left(1992^{2}: 11\right)$ ha puntualizado que

«la problemática teórica, el debate en torno a los lenguajes (audio)visuales no puede entenderse sino a condición de ver en aquella el lugar de cruce de una evolución histórica y un desarrollo técnico»

Es el caso del concepto mismo de imagen, que ha pasado de considerarse como imagen mental, en el sentido de la psicología cognitiva, a imagen «material», construida sobre significantes distintos según los casos (escultura, pintura, cine, etc.). Y es que, bajo una perspectiva semiótica, la imagen deja de ser considerada como símbolo de contenidos mentales para pasar a considerar que ante todo significa información, esto es, como señala, Rey (1992: 24):

«La concepción semiótica ha llevado a cabouna segunda rehabilitación de la imagen. Si los motivacionistas la despojaron de su simple función atractiva, los semióticos a su vez la desposeyeron de toda referencia psicológica y la entendieron como ente autónomo capaz de significar por sí mismo. Igualmente estimaron que un anuncio publicitario es una comunicación mixta en la que tanta importancia tiene el texto como la imagen revelando así una dimensión de la imagen hasta entonces desconocida: su capacidad de transmitir información»

La imagen ha sido abordada de formas distintas a lo largo del tiempo y, como señala Gauthier (1986: 16), no ha sido objeto de una ciencia que le sea propia desde el Renacimiento, hecho con indudables motivaciones históricas e ideológicas, puesto que, como demuestra este autor en el estudio que realiza de distintos elementos constitutivos de la imagen, su entendimiento ha estado marcado por concretos intereses estéticos e ideológicos. Es el caso, entre otros, de la perspectiva lineal, que en Europa occidental - frente a Oriente - se impone como forma determinada de la profundidad realista a la par que triunfaba el espíritu racionalista y científico y en el momento histórico en que el feudalismo era sustituido por el capitalismo (Gauthier, 1986: cap. II). $Y$ es que, como pone de manifiesto este autor, la imagen occidental es un sistema cerrado, convencional, que simula el mundo, hecho que contradice las más fundadas teorías que se han producido al respecto, ya que las imágenes no reproducen ni sustituyen la realidad, sino que dan una serie de elementos para que el receptor pueda llevar a cabo su 
particular interpretación de tal realidad. La pretensión de «realismo» hay que situarla en un momento de ascenso de la burguesía apasionada por unos éxitos científicos que iban íntimamente unidos a su triunfo. O sea, que

«por poco que se examine con atención las relaciones de la imagen con lo real, cualquiera que sea el lado por el que se examine el problema, resulta que la imagen remite ante todo a sí misma. Esto no quiere decir que nada tenga que ver con lo real (...) sino, al menos, que mantiene relaciones ambiguas con lo real percibido que la teoría ha situado, de modo abrumador, en el centro de sus preocupaciones, con el éxito que se le conoce» (Gauthier, 1986: 60).

Tal cuestionamiento, bastante generalizado en la actualidad en los estudios sobre la imagen, es uno de los síntomas más significativos de la crisis del concepto de iconismo, que veremos más adelante.

2.0. Aludir, aunque sea brevemente, a algunos de los problemas más destacados que se están dando en torno al mundo de lo audiovisual, nos ha parecido absolutamente necesario para poder tratar algunas de las cuestiones que se están debatiendo en la retórica audiovisual. En los años sesenta se empezó a llamar la atención sobre la retórica de la publicidad sobre todo, hecho motivado por la extensión y cercanía de tal manifestación audiovisual, a la vez que por su marcada y clara intencionalidad persuasiva. En la actualidad disponemos de no pocos estudios que se sitúan en el mismo campo, aunque presenten diferencias de mayor o menor magnitud, dependiendo de los casos; este campo no es otro que el de la retórica de la publicidad, la semiótica de la publicidad, etc. En estos casos, y en otros que se centran en el cine, la televisión, etc., la cuestión nodal es la misma: el reto que actualmente supone la imagen tanto para receptores críticos como para receptores de a pie, reto que conlleva la necesidad de establecer una serie de parámetros que hagan posible la lectura de la imagen y que terminen, en consecuencia, con la mera recepción pasiva, acrítica y equívocamente significante en más de una ocasión. Tal reto tiene un enorme interés a todos los niveles, pero en la enseñanza parece cobrar una consideración especial ante la acuciante necesidad de mostrar a alumnos de distintos niveles una forma operativa de llegar a aprehender el significado de manifestaciones audiovisuales que les llegan constantemente por las vías más diversas, pero sobre todo de forma abundante, variada y con más frecuencia que el tradicional discurso literario. 
En este deseo de llegar a establecer formas pertinentes de leer la imagen, la retórica ha pasado a ocupar un lugar destacado, aunque más importante en unas manifestaciones (la publicidad, por ejemplo) que en otras, como se ha dicho ya. Roland Barthes fue el autor pionero en este campo, que pronto vio cómo sus propuestas eran seguidas por Jacques Durand y Georges Péninou, sobre todo. En los tres casos se trata de estudios que presentan una fuerte dependencia de la lingüística. Al margen ya de esta disciplina surgen numerosos ensayos que, si bien carecen de unanimidad, han ido mostrando propuestas diversas; es el caso de autores tan variados como Umberto Eco, Alberto Farassimo, Jean Marie Floch y otros (Pérez Tornero, 1982: 119 y ss.; Rey, 1992: 27 y ss.). Aquí nos vamos a ocupar de dos autores cuyas teorías encierran no poco interés en el actual panorama de los estudios culturológicos y retóricos: Iuri M. Lotman y Jean-Marie Klinkenberg.

2.1. Como todo el mundo sabe, I. Lotman es el maestro de la escuela semiótica de Tartu-Moscú, en la que hay que situar el nacimiento de la llamada semiótica de la cultura. Dentro de este ámbito teórico, la retórica ocupa su propio lugar, si bien es cierto que Lotman sólo ha dedicado, de forma sistemática y exclusiva, un ensayo tardío a la vieja disciplina. Se trata de «La retórica» (1981), estudio en el que el teórico intenta explicar y ubicar la antigua disciplina en la nueva realidad generada por la recuperación que de ella se ha producido en el siglo $\mathrm{XX}$ y los cambios operados en la misma época en torno a diversos paradigmas teóricos.

En cualquier caso, la presencia de la lingüística en este campo no es desconocida ni negada por Lotman, que da cuenta de ella fielmente, sobre todo de dos concepciones lingüísticas de la retórica que se han producido en el siglo $\mathrm{XX}$ : se trata, en primer lugar, de una acepción linguística a secas, en la que se consideran las reglas de construcción del discurso por encima del nivel de la frase; $y$, en segundo lugar, la concepción según la cual la retórica se entendería como «semántica poética» y estudiaría los tipos traslaticios, esto es, las figuras. Una tercera acepción, aunque conectada con la linguiística en tanto que «poética del texto", apunta ya en una dirección amplia, pues contempla el estudio de las relaciones intertextuales y el funcionamiento social de textos como formaciones semióticas unitarias.

Esta triple concepción de la retórica, al igual que otras muchas teorías de Lotman, parte de presupuestos linguísticos para situarse en un nivel semiótico en el que los condicionamientos culturales cobran una importancia notable. Se trata, como hemos estudiado en otro lugar 
(Pulido Tirado, 1995), de una posición teórica que, sin romper con la linguiisticidad de los estudios estructurales y semióticos en su primera época, avanza notablemente hacia una posición distinta. Muestra de ello es que, al señalar los dos enfoques posibles que se pueden adoptar ante la gramática del texto, esto es, primero, la estructura retórica se deriva automáticamente de leyes del lenguaje y representa la realización de éstas en el nivel de la construcción de textos unitarios, y, segundo, entre la unidad lingüística y la unidad retórica del texto no existe una diferencia esencial, este autor se inclina por la segunda. Tal preferencia conlleva la idea básica de que

«La estructura retórica se introduce en el texto verbal desde afuera, siendo una ordenación complementaria de éste» (Lotman, 1981: 39).

Al ser ajena a los principios estructurales del texto, la retórica es percibida subjetivamente y desempeña un papel fundamental en la definición de textos, ya que la introducción, por ejemplo, de un fragmento de texto no artístico en otro artístico es reconocida como introducción extraña en el segundo texto, lo que conlleva una carga retórica en tanto que toda retórica es percibida como una estructura extraña. Y es que todo texto artístico se presenta ante nuestra conciencia como texto retóricamente organizado que, como tal, presenta una alta retoricidad en los elementos que nos indican que nos hallamos, precisamente, ante un texto.

Por otra parte, los vínculos estructurales del texto reducen la independencia de las unidades que lo constituyen y aumentan la cohesión del texto hasta el punto de poder afirmar que

«el texto aspira a convertirse en una "gran palabra" separada con un sólo significado general» (Lotman, 1981: 37).

palabra secundaria en el texto artístico - recordemos que para Lotman existe un sistema primario y un sisterna modalizante secundario: el arte en general-, que, para el teórico eslavo, es siempre un tropo, con lo que el discurso artístico pasa a tener un elevado número de dimensiones que hacen imposible una relación o traducción unívoca, siendo posibles únicamente la equivalencia convencional y algunos tipos de analogía. Es lo que sucede en las relaciones retóricas; que pueden 
detectarse también en el estudio de la cultura actuando de forma similar, puesto que en las culturas orientadas a la organización retórica cada eslabón de la jerarquía creciente en la organización semiótica produce un aumento numérico de las dimensiones del espacio estructural de sentido, de tal forma que cada eslabón de la jerarquía no se puede expresar con los medios precedentes ya que sólo representa una imagen o presencia incompleta del mundo. La organización retórica estaría en la base de la cultura como tal y convertiría cada nuevo escalón en un misterio para los inferiores, por lo que

«en la retórica (como, por otra parte, en la lógica) se refleja el principio universal tanto de la conciencia individual como de la colectiva (la cultura)» (Lotman, 1981: 38).

Pero, antes de buscar la explicación a la universalidad atribuida a la retórica, conviene que nos detengamos en otros aspectos de la cultura que se encuentran íntimamente relacionados con la retórica. En principio, destaca el hecho de que Lotman considere como uno de los universales de la cultura humana la oposición «retorismo/antirretorismo», ya que la retórica puede entrar a formar parte de la tradición y, por tanto, de las expectativas de los lectores, pasando en tal caso el tropo en cuestión a depositarse en el lenguaje común y a dejar de ser percibido activamente como retórico. Un ejemplo de tal hecho sería el antirretoricismo del cine neorrealista, que surgiría por oposición a la retórica desgastada de las grandes epopeyas cinematográficas seudohistóricas y las comedias del gran mundo, y, en sentido contrario, el barroco de las obras de Fellini, que tendería a una rehabilitación retórica.

La retórica, pues, tiene un carácter general que, en una determinada sociedad, afecta a todas las manifestaciones culturales, ya sean literarias o no literarias, ya sean científicas o no.

Pero la cultura desempeña una destacada función en relación con esta disciplina: determinar las relaciones de analogía o equivalencia que se producen en algún grupo de textos o de situaciones comunicativas. Esta afirmación parece obvia, pero no por ello es menos importante, ya que nunca está de más señalar el carácter no esencial, no ahistórico ni eterno, de las distintas manifestaciones culturales humanas, las cuales sólo se explican por su concreta ubicación dentro de un momento histórico determinado que las condiciona de múltiples formas. Si en el campo literario tal hecho es hoy innegable, en el terreno 
de lo audiovisual tampoco ha sido ignorado. Por ello, no puede sorprender que Vilches (19925: 10) afirme que

«Las imágenes en la comunicación de masas se transmiten en forma de textos culturales que contienen un mundo real o posible, incluyendo la propia imagen del espectador. Los textos le revelan al lector su propia imagen»

Más allá de la simple consideración cultural de la retórica y de la imagen, no podemos dejar de mencionar aquí, aunque sea de pasada, el estudio semiótico de la ideología que propone Umberto Eco, ya que la ideología está inextricablemente unida a distintas manifestaciones audiovisuales que genera nuestra sociedad. Para Eco, cuando se oculta la parcialidad dentro de un discurso determinado, se pasa de la persuasión al fraude, a una posición ideológica. La ideología, en tanto que visión parcial e inconexa del mundo que ignora las múltiples interconexiones del universo semántico, oculta también. Según esta teoría, las razones prácticas por las que algunos signos se han producido junto a sus interpretaciones ya que el olvido produce falsa conciencia. Por tanto

«Una teoría de los signos (que parecía tan independiente de los estados del mundo, dispuesta siempre a nombrarlos y mediante signos exclusivamente) demuestra en este punto su poder práctico heurístico: al mostrar las conexiones secretas y ocultas en un sistema cultural determinado, revela las formas en que un trabajo de producción de signos puede respetar o traicionar la complejidad de ese retículo semántico al adecuarlo al (o separarlo del) trabajo humano de transformación de los actos del mundo» (Eco, 1977: 415-416).

En definitiva, lo que U. Eco hace es llamar la atención desde su peculiar perspectiva semiótica sobre un hecho que no sólo tratan los estudiosos de las manifestaciones audiovisuales, sino que en más de una ocasión se convierte en la razón de ser de estudios que pretenden establecer rigurosamente el impacto social de tales manifestaciones $y$, debido precisamente a la existencia de una influencia y una extensión que van aumentando cada día, establecer una teoría crítica (ya sea sociológica, marxista, semiótica, etc.) que nos muestre con la mayor nitidez posible la manipulación o tergiversación que de la realidad producen distintos discursos audiovisuales, los cuales tienen cada vez una presencia mayor en nuestras vidas. 
Volviendo a Lotman, queda pendiente la explicación que ofrece el teórico de la universalidad retórica. La explicación está, sin duda, emparentada con la teoría que diera Jakobson (1956) de la metáfora y la metonimia basándose en postulados saussureanos y relacionando los procedimientos en cuestión con la afasia. En este segundo sentido, el teórico de Tartu indaga en el cerebro humano para intentar establecer la razón de algunos de sus asertos. El punto de partida es el siguiente:

«Las investigaciones de lo específico del funcionamiento de los grandes hemisferios del cerebro humano revelan una profunda analogía con el dispositivo de la cultura como intelecto colectivo: en ambos casos descubrimos la presencia de, como mínimo, dos modos esencialmente distintos de reflejar el mundo y de elaborar nueva información con los posteriores complejos mecanismos de intercambio de textos entre esos sistemas. En los dos casos observamos, en líneas generales, una estructura análoga: diríase que en los marcos de la conciencia están presentes dos conciencias» (Lotman, 1981: 23).

Éstas serían, primero, la que opera sobre un sistema discreto de codificación y forma textos que se constituyen como cadenas lineales de segmentos unidos; en este caso, el portador fundamental del significado es el segmento o signo y el texto o cadena de segmentos es secundario en tanto que su significado deriva del significado de los signos. Segundo, el texto es primario, no es discreto por naturaleza, sino continuo. Por tanto, los marcos de la conciencia individual y colectiva encerrarían dos tipos de generadores de textos: uno basado en el mecanismo de la discreción y otro, que sería continuo. Entre ambos existiría un constante intercambio de textos y de mensajes realizado en forma de traducción semántica. Sin embargo, la yuxtaposición de textos discretos y no discretos es, en principio, imposible, aunque se produce. Y las consecuencias de esta aproximación es la imposibilidad de traducir que se sustituye por una equivalencia aproximativa, la cual estaría condicionada por un determinado contexto psicosocial y semiótico común a ambos sistemas. En estos casos surge el tropo semántico como consecuencia de un acercamiento irregular entre sistemas que produce nuevos vínculos de sentido. De esto se deduce que

«En este respecto los tropos no son ornamento externo, cierto género de aplicación que se pone sobre el pensamiento desde afuera: ellos constituyen la esencia del pensamiento creador, y su esfera se extiende incluso más allá del arte: pertenece a la creación en general» (Lotman, 1981: 24). 
La fundamentación «biológica» de la retórica, debidamente desarrollada y probada, podría producir una auténtica revolución en nuestra concepción de esta disciplina, pues, sin duda, obligaría a revisar la mayor parte de las ideas que se han producido en torno a ella y han determinado su suerte a lo largo de varios siglos. En lo que se refiere al ámbito audiovisual, no tratado de forma específica por Lotman, habría que reconocer que existe una analogía con lo literario, sólo que dicha analogía no estaría ya basada en una disciplina externa como la lingüística, sino en determinados mecanismos que caracterizan y rigen el cerebro humano. Tras cimentar este punto inicial, el estudioso tendría que abordar otras cuestiones fundamentales, si bien desde otra perspectiva, como son los condicionamientos de las distintas manifestaciones retóricas, sus características concretas, sus respectivos soportes, etc., factores todos éstos importantes para fundamentar una retórica (audio)visual con objeto propio y características definidas.

2.2. Esto es lo que pretende, desde otra posición retórica, JeanMarie Klinkenberg, miembro del grupo $\mu$ de Lieja que, desde los años sesenta, viene realizando aportaciones diversas en el campo de la retórica.

En 1983 Klinkenberg se planteaba ya abiertamente el tema que nos ocupa en un trabajo lleno de sugerencias, «El signo icónico. La retórica icónica. Proposiciones», que no es la primera manifestación importante del grupo sobre la retórica (audio)visual, pues en 1979 ya habían publicado Trois fragments d'une rhétorique de l'image, y, en 1980, Plan d'une rhétorique de l'image. El profesor de Lieja no duda en apostar por la posibilidad de constituir una retórica general argumentando que, si existe una retórica lingüística que se puede definir de forma general como el estudio de los empleos del lenguaje en que la función comunicativa no es primaria, y si existen leyes generales de la significación y de la comunicación, se puede afirmar que existe una retórica general que puede dar cuenta de todos los fenómenos que se producen en todos los campos semióticos. Dentro de esta retórica habría que situar la retórica de lo visual o retórica icónica, de casi nulo desarrollo, como reconoce el profesor de Lieja. Los problemas con los que se enfrenta la constitución de esta retórica son, por un lado, el excesivo apego de la semiótica visual a la crítica del arte que produce un apego constante a enunciados particulares por individualizados y, por otro, al «imperialismo lingüístico» que ejerce, a su criterio, una influencia negativa, pues, si se produce tanto una aceptación de tal imperialismo como su rechazo, los resultados son negativos, ya que en 
el último caso se rechazan también otras disciplinas como la óptica, la fisiología o la psicología de la recepción, las cuales pueden contribuir positivamente a la constitución de una retórica visual.

Klinkenberg parte del concepto de icono, que no cuestiona, y que define como relación triple entre significante icónico, tipo y referente. Esto le permite distinguir en el signo visual global, considerado como realidad empírica, dos conceptos teóricos: el signo icónico y el signo plástico. Las definiciones son las que siguen:

«Entenderemos por signo icónico el signo analógico, que se refleja miméticamente a un objeto de la realidad, y por signo plástico el sistema de las formas y de los colores independientemente del mimetismo» (Klinkenberg, 1985: 13).

Esta distinción le permite realizar, a su vez, otra en el seno de la semiótica, puesto que, a su juicio, existirían dos retóricas distintas. Si en principio hay que distinguir entre una retórica del signo icónico y una retórica del signo plástico, la retórica icónica se dividiría, a su vez, en, primero, una retórica del reconocimiento o retórica tipológica, y, segundo, en una retórica de la transformación o retórica transformativa. La primera se basaría en la consideración de la retórica como todo estímulo visual que puede referirse a un tipo, pero que no se conforma a ese tipo; la segunda procedería de la multiplicidad y variabilidad de las reglas de transformación en un mismo enunciado.

Tras esta definición y clasificación queda pendiente la clasificación de las figuras que Klinkenberg, de acuerdo con su concepto de semiótica icónica, ofrece en un trabajo posterior, de 1988, «Fundamentos de una retórica visual» (1990), en el que, desde una perspectiva reductora, entiende que

«la retórica es una transformación reglada de los elementos de un enunciado, transformación que obliga al receptor a sobreponer dialécticamente al grado percibido un grado concebido» (Klinkenberg, 1985: 43).

De aquí que la operación retórica se considere constituida por tres fases: la producción del desvío, la identificación del desvío y la reevaluación del desvío o estudio de la relación entre el grado percibido y el grado concebido, siendo las dos últimas de gran importancia para la clasificación de figuras en la retórica visual que propone. 
Tras ofrecer estos fundamentos y poner de manifiesto la dificultad de establecer un «grado cero», Klinkenberg (1985: 48 y ss.) ofrece la prometida clasificación de las figuras icónicas, clasificación enormemente coherente en relación a los fundamentos teóricos que la sustentan, pero cuestionable en la medida en que tales fundamentos pueden ser cuestionados a su vez. En cualquier caso, no puede negarse que la taxonomía que ofrece este autor supone un avance notable en relación a otras anteriores, como la de Durand o Péninou, quienes recogen algunas propuestas realizadas por Roland Barthes (1964) en tanto que se trata de un estudio de las figuras retóricas que se circunscribe al ámbito que le es propio, aunque no ignora algunas operaciones retóricas básicas y generales como la adjunción, la supresión, la sustitución y la permutación.

La propuesta de Klinkenberg supone, a nuestro juicio, un avance importante en este campo. Sin embargo, hay dos elementos teóricos en su sistema que lo hacen cuestionable: el signo icónico y el controvertido «grado cero».

En lo que se refiere al primero, es conocido el cuestionamiento que de la iconicidad se está produciendo en la semiótica desde hace años, si bien es cierto que desde los orígenes mismos de la disciplina el concepto de icono ha ocupado un lugar importante en las distintas disquisiciones teóricas.

Podemos recordar que Ch. Morris atribuía a los objetos icónicos las mismas propiedades que las del objeto al que aludían, las de su denotata; y Peirce afirmaba que un signo es icónico cuando puede representar un objeto por la semejanza (Vilches, 1992: 16 y ss.). Entre los muchos autores que han cuestionado esta categoría tenemos que destacar a U. Eco por la persistencia y claridad con que lo hace. En una obra madura como es el Tratado de semiótica general (1977: 287 y ss.) es sumamente explícito al respecto. Los iconos no son signos «motivados por», «semejantes a» ni «vinculados naturalmente» a su objeto, aunque reconoce que

«los signos icónicos no tienen las "mismas" propiedades físicas del objeto, pero estimulan una estructura perceptiva "semejante" a la que estimularía el objeto imitado. En este caso, lo que se trata de establecer es el cambio de los estímulos materiales, qué es lo que sigue invariable en el sistema de relaciones que constituye la Gestalt perceptiva» (Eco, 1977: 290).

Y es que, como ha señalado Vilches (1992: 22): 
«según Eco, representar icónicamente un objeto es transcribir según convenciones gráficas propiedades culturales de orden 6́ptico y perceptivo, de orden ontológico (cualidades esenciales que se le atribuyen a los objetos) y de orden convencional, es decir, el modo acostumbrado de representar objetos».

De la posición de Eco se deduce claramente que los signos icónicos no pueden ser abordados como signos verbales, esto es, signos que se descomponen en unidades pertinentes, articulados, etc. - aunque pueden distinguirse unidades pertenecientes al ámbito espacio-temporal propio de la imagen-, por lo que, junto a la «falacia naturalista», parece que esta teoría termina finalmente con la dependencia de la linguística. Sin embargo, hay que decir que esta posición teórica no le sigue, en el terreno práctico, un estudio de las figuras retóricas (audio) visuales tan innovador como pudiera pensarse, ya que Eco cuestiona el clásico concepto de icono, pero no la retórica clásica, que es la que convierte en modelo de una clasificación realizada tomando como punto de referencia la Retórica de Aristóteles y proponiendo establecer una correlación entre las manifestaciones retóricas visuales y verbales sin descartar que alguna de las últimas no se corresponda con alguna de las primeras; en tal caso, habría que determinar si existe un artificio visual nuevo y, si es así, ver si puede ser catalogado y comparado (Eco, 1972).

Klinkenberg no cuestiona el concepto de icono en el mismo sentido por considerar que entre los tres elementos que constituyen el signo icónico, tipo, referente y significante, en el eje significante-tipo no existe ningún elemento material común con las cosas; sin embargo, no ocurre igual en el eje signo-referente. El profesor belga, al distinguir la existencia de estos dos ejes, señala la existencia de motivación en el aspecto del referente cuando se pueden aplicar transformaciones que permitan la sustitución del referente; y en el aspecto del tipo, cuando el significante resulta conforme al tipo. En cualquier caso, aunque el teórico reconozca que con la motivación muere el concepto de «representación», tal eliminación no se produce más que de forma parcial puesto que, aunque considere que es imposible hablar de representación como traducción visual del signo, afirma que la representación actúa siempre en el eje representante-significante, en tanto que representación implica singularización, y el referente puede ser no sólo un objeto real sino también, por ejemplo, una imagen mental.

El segundo concepto que señalábamos antes, el de la posible existencia de un «grado cero», es, sin duda, uno de los más controvertidos 
no sólo en la retórica sino en la teoría literaria en general. No nos vamos a extender aquí en su crítica y en las múltiples implicaciones que su propia defensa o cuestionamiento han tenido a lo largo del tiempo, pues ello nos conduciría poco menos que a una revisión de buena parte del pensamiento literario tradicional. Baste decir que el uso de tal concepto a estas alturas es arriesgado, hecho que sin duda no ignora Klinkenberg, y más cuando la demostración de su existencia parece más que cuestionable.

En suma, y para terminar, no se puede decir que los discursos audiovisuales estén siendo ignorados frente al tradicional discurso literario, si bien es cierto que el último goza de mayor atención a nivel académico que los primeros. La imagen constituye el gran reto de nuestra época y ello no puede ignorarse. Los estudios de retórica (audio)visual han evolucionado desde una posición lingüística, y como tal, a nuestro juicio, errónea, hacia perspectivas semióticas que buscan hacer de la imagen un objeto de conocimiento con valor propio que permita constituir una vía de estudio fundamental y operante. Las perspectivas abiertas son variadas, y los casos de Lotman y Klinkenberg son una muestra de ello, pero falta una mínima coherencia de criterios que pueda hacer posible la constitución de un método sólido, constitución que no hay que descartar si consideramos que las vías abiertas serán desarrolladas en el futuro, $y$, teniendo en cuenta la comunidad de intereses, no se puede eliminar la posibilidad de que en un momento determinado se intente llevar a cabo una unificación de criterios epistemológicos, aunque, como estamos viendo en los estudios literarios contemporáneos, la pluralidad y la divergencia de opiniones encierran cierta riqueza y son difíciles - cuando no imposibles- de eliminar.

\section{Referencias bibliográficas}

Barthes, Roland (1964). «Rhétorique de l'image». Communications 4: 40-51. ECO, UMBERTO (1972). La estructura ausente. Barcelona: Lumen.

- (1977). Tratado de semiótica general. Barcelona: Lumen, $1991^{5}$.

GHAUTIER, GUY (1986). Veinte lecciones sobre la imagen y el sentido. Madrid: Cátedra.

GRUPO $\mu$ (1979). Trois fragments d' une rhétorique de l'image. Universidad de Urbino. (Documents de travail, série $\mathrm{F}, \mathrm{n}^{\mathrm{0}}$ 82-83.)

- (1980). «Plan d'une rhétorique de l'image». Kodikas-Code 3: 249268. 
JAKOBSON, ROMAN (1956). «Dos aspectos del lenguaje y dos tipos de trastornos afásicos». En Fundamentos del lenguaje, Jakobson, R. y Halle, M., 97-143. Madrid: Ayuso, $1973^{2}$.

KLINKENBERG, JEAN-MARIE (1985). «El signo icónico. La retórica icónica. Proposiciones». En La crisis de la literariedad, M. Á. Garrido (ed.), 171184. Madrid: Taurus, 1987.

- (1990). «Fundamentos de una retórica visual». En Investigaciones semióticas III, Romera Castillo, J.-Yllera, A. (eds.), 39-57. (Actas del III Simposio Internacional de la Asociación Española de Semiótica. Sevilla, 5-7 dic. 1988.) Madrid: Visor, I, 1990.

LOTMAN, IURI M. (1970). Estructura del texto artístico. Madrid: Istmo, $1982^{2}$.

- (1981). «La retórica». Escritos. Revista del Centro de Ciencia del Lenguaje (Benemérita Universidad Autónoma de Puebla) 9, enerodiciembre de 1993, 21-46.

Pérez TORNERo, J.M. (1982). La semiótica de la publicidad. Análisis del lenguaje publicitario. Barcelona: Mitre.

Pulido Tirado, Genera (1995). «La semiótica de I. Lotman en el marco de la teoría de la literatura contemporanea». En Reunión Internacional in Memoriam Iuri M. Lotman (Granada, octubre, 1995), e. p.

REY, JUAN (1992). La significación publicitaria. Sevilla: Alfar.

VILCHES, LORENZO $\left(1992^{5}\right)$. La lectura de la imagen. Prensa, cine, televisión. Barcelona-Buenos Aires-México: Paidós Comunicación.

Zunzunegui, SANTos $\left(1992^{2}\right.$ ). Pensar la imagen. Madrid: Cátedra-Universidad del País Vasco. 